\title{
Modeling Analysis and Simulation of Wheel Suspension System's Response for Quarter Car Model by Using 20-sim Software for Honda Civic Lx 2019 Sedan
}

\author{
Hamid Hussain Hadwan ${ }^{1 *}$, Mushrek Alawi Mahdi', Ahmed Waleed Hussein ${ }^{2}$ \\ ${ }^{1}$ Department of Automobile Engineering, Faculty of Automobile Engineering Department, College of Engineering/ Al-Musayab, \\ University of Babylon, Al Najaf street, 51002 Babylon, Iraq \\ 2 Department of Energy Engineering, Faculty of Energy Engineering Department, College of Engineering/ Al-Musayab, University \\ of Babylon, Al Najaf street, 51002 Babylon, Iraq \\ *Corresponding author, e-mail: met.hamed.huss@uobabylon.edu.iq
}

Received: 21 March 2021, Accepted: 09 September 2021, Published online: 17 November 2021

\begin{abstract}
This paper exhibits a study of car passive and active- suspension system to improving drive exhilarate to passengers while also enhancing vehicle stability by decreasing the effect of oscillation on the suspension. Modeling and simulation by using the bond diagram. They much concede a prime arrangement of the machine to the exterior surrounding: street quality, atmospherically circumstances, while guarantying driver as well as passengers, major safeness and more potentially exhilarate. Automotive aid it course manners. The result cleared this action plan at different set during the vehicle mean, but particularly in evolution level. It is also clear the proportion of suspension system's mass to the vehicle's mass. Also graphical representation of suspension system' parameters like vertical passenger displacement, potential energy of mass of suspension system and acceleration. To foretell the comportment of a car, it is necessary to make design, modeling, and simulation. Honda Civic Lx 2019 sedan car has used for modeling, and simulation.
\end{abstract}

Keywords

simulation, Bond graph, 20-sim, wheel suspension system

\section{Introduction}

Since the dawn of the automobile era, one of the most important priorities of researchers has been the suspension system. To this point, people demands have risen with time, and several studies have been conducted to boost the effectiveness of vehicle suspensions in order to increase vehicle convenience while driving, to reach this target.

The quarter version of modeling the automobile with two degrees of freedom presented in the first half of this study. Section 2 discusses a touch simulation consequence from the 20-sim software. The targets of the present paintings are to have a look at the Bond graph used to model the dynamic behavior of automobile vehicles: technique, modeling, and analysis of suspension for a quarter version of the automobile.

\section{Related work}

Many studies had been causing to signify difference road profiles borrowed with the aid of automobiles [1, 2].
In various research studies of varying complexity of models based on the intended application, quarter automobile models with two degrees of freedom that manage transverse movements of the vehicle have been used to manage perpendicular movements of the machine. Defined the velocity of vibration converted to passengers and limits of comfort [3-6]. Semi model automobile with four degrees of freedom [7-9] also a seven-degree-of-freedom complete orthogonal simulation of the automobile [10-13].

The technique Bond diagram will be deployed in this paper [14-16]. For modeling suspension quarter, it has formerly worked on this approach $[17,18]$.

\section{Mathematical modeling and analysis}

The elements that have an effect on the state with vibration of the car suspension gadget in particular positioned internal the spring in suspending, damping, and elastic damping properties of tires. The automobile suspension 
model can simplify by way of the use of the different vibration of the body and the wheel, as well as the rotational of roll motion underneath consideration. Those elements employed the suspension model on a regular bases to make determining its kinematic characteristics easier. The damper is put in accordance with the elastic issue inside the suspension device in the suspension gadget to improve the car's balance and lessen trembling.

The system version simplified to a single-DOF model with a $1 / 4$ suspension base a spring and damper as verified (Figs. 1, 2). The gadget of motion differential equations established in preserving with the D'alembert principle. The nonlinear dynamic characteristics of the suspension system analyzed.

Damping constant related to damping ratio. The model represented with the aid of using a second-order massspring-damper system. The spring and the damping coefficients had selected to regulate the response of suspension. Spring constant associated with a natural frequency. The balance between usual overall performance and rider comfort $y$ as shown in Fig. 3.

State-Space (SS) model the suspension-system. The simplified transfer function produced by:

$\operatorname{TF}($ Transfer Function $)=\frac{Y_{s}}{Y_{\text {road }}}=\frac{b s+k}{m s^{2}+b s+k}$,

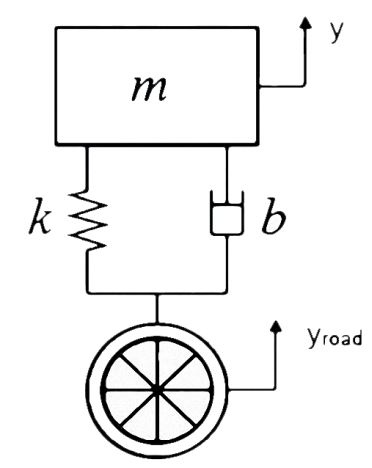

Fig. 1 Single degree-offFreedom quarter-vehicle suspension model

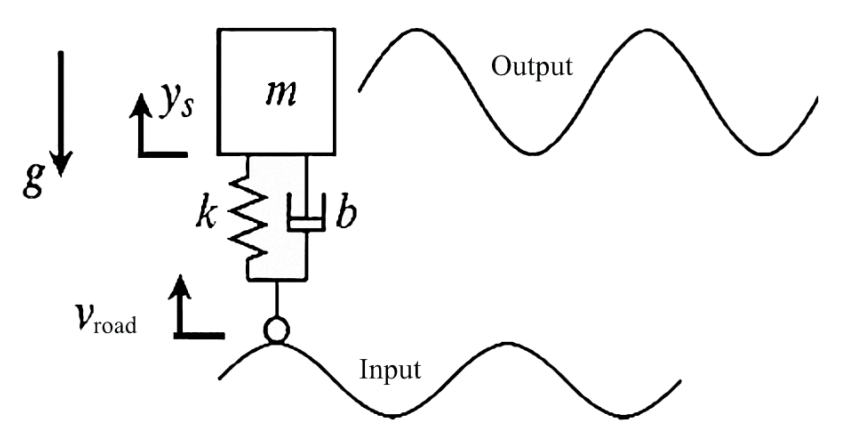

Fig. 2 Mechanical model of quarter-car suspension

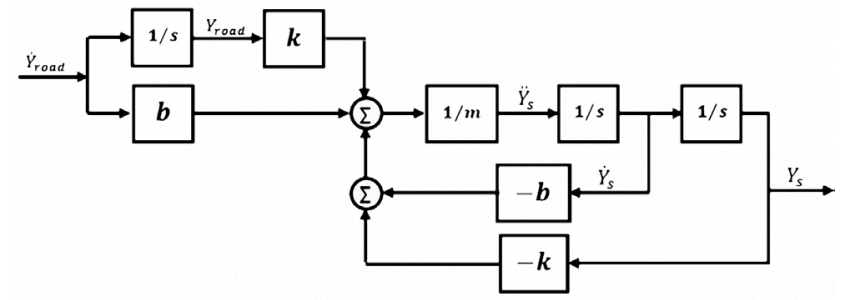

Fig. 3 The block diagram

$\frac{Y_{s}}{Y_{\text {road }}}=\frac{s V(s)}{s V_{\text {road }}(s)}=\frac{V(s)}{V_{\text {road }}(s)}=\frac{b s+k}{m s^{2}+b s+k}$.

For Honda Civic Lx sedan 2019: the curb mass $=1255 \mathrm{~kg}$, mass distribution [front $/$ rear] $=60 \% / 39.4 \%$. Assume there is an additional weight that causes the mass distribution on the wheels to be equal.

Assume a total mass $=1600 \mathrm{~kg}$.

The mass of quarter suspension $=m_{2} \approx 41.7875 \mathrm{~kg} \approx 42 \mathrm{~kg}$. $m_{1}=360 \mathrm{~kg}, b=2000(\mathrm{~N} \mathrm{~s} / \mathrm{m})$ and $k=200000$.

Substituting in Eqs. (1) and (2) gives:

$\mathrm{TF}=\frac{2000 s+200000}{360 s^{2}+2000 s+200000}=\frac{5.56 s+555.56}{s^{2}+5.56 s+555.56}$

Equation (3) leads to

$a_{1}=b_{1}=5.56$,

$a_{2}=b_{2}=555.56$.

In upper companion, control canonical is from

$A=\left[\begin{array}{cc}-a_{1} & -a_{2} \\ 1 & 0\end{array}\right]=\left[\begin{array}{cc}-5.56 & -555.56 \\ 1 & 0\end{array}\right]$

$B=\left[\begin{array}{l}1 \\ 0\end{array}\right]$,

$C=\left[\begin{array}{ll}5.56 & 555.56\end{array}\right]$

In lower companion, control canonical is from

$A=\left[\begin{array}{cc}0 & 1 \\ -a_{2} & -a_{1}\end{array}\right]=\left[\begin{array}{cc}0 & 1 \\ -555.56 & -5.56\end{array}\right]$

$B=\left[\begin{array}{l}1 \\ 0\end{array}\right]$

$C=\left[\begin{array}{ll}555.56 & 5.56\end{array}\right]$. 


\subsection{Poles, zeros and stability}

Poles of the open-loop system produced by solving:

Det. $|s I-A|=0$,

Det. $\left|\left[\begin{array}{ll}s & 0 \\ 0 & s\end{array}\right]-\left[\begin{array}{cc}-5.56 & -555.56 \\ 1 & 0\end{array}\right]\right|=0$,

Det. $\left|\left[\begin{array}{ll}S & 0 \\ 0 & S\end{array}\right]-\left[\begin{array}{cc}-5.56 & -555.56 \\ 1 & 0\end{array}\right]\right|=0$,

$s^{2}+5.56 s+555.56=0$.

Roots of Eq. (9) give poles of the open-loop system:

$p_{1} \times p_{2}=-27.8 \pm 23.4 i$.

Zero of the loop system produced by solving the standard Eqs. (11) and (12):

Det. $\left|\begin{array}{cc}s I-A & -B \\ C & D\end{array}\right|=0$,

Det. $\left|\left[\begin{array}{ccc}s+5.56 & 555.56 & -1 \\ -1 & s & 0 \\ 5.56 & 555.56 & 0\end{array}\right]\right|=0$,

$(s+5.56)(0)-(555.56)(0)-(1)(-1 \times 555.56-5.56 s)=0$,

$5.56 s=-555.56$

zero at $s=-99.92 \Rightarrow$ the system is stable.

Controllability is

$A=\left[\begin{array}{cc}-5.56 & -555.56 \\ 1 & 0\end{array}\right]$,

$B=\left[\begin{array}{l}1 \\ 0\end{array}\right]$.

Controllability matrix (CO) leads to Eqs. (13) and (14):

$C O=\left[\begin{array}{ll}B & A B\end{array}\right]$,

$A B=\left[\begin{array}{cc}-5.56 & -555.56 \\ 1 & 0\end{array}\right] \times\left[\begin{array}{l}1 \\ 0\end{array}\right]=\left[\begin{array}{c}-5.56 \\ 1\end{array}\right]$,

$C O=\left[\begin{array}{ll}B & A B\end{array}\right]=\left[\begin{array}{cc}1 & -5.56 \\ 0 & 1\end{array}\right]$,

$\operatorname{Det}(C O)=1$.

The system $=$ controllable because determinant $\neq$ to zero

Rank of controllability matrix $=2 \Rightarrow$ All states are controllable.
To check observability:

$A=\left[\begin{array}{cc}-5.56 & -555.56 \\ 1 & 0\end{array}\right] \quad C=\left[\begin{array}{ll}5.56 & 555.56\end{array}\right]$.

Observability matrix $\left(O B \_M A T\right)$ produced by solving Eqs. (15) and (16):

$O B_{-} M A T=\left[\begin{array}{c}C \\ C A\end{array}\right]$,

$C A=\left[\begin{array}{ll}-5.56 & -555.56\end{array}\right] \times\left[\begin{array}{cc}-5.56 & 555.56 \\ 1 & 0\end{array}\right]$

$=\left[\begin{array}{ll}524.65 & -3088.9\end{array}\right]$,

$O B_{-} M A T=\left[\begin{array}{c}C \\ C A\end{array}\right]=\left[\begin{array}{cc}5.56 & 555.56 \\ 524.65 & -3088.9\end{array}\right]$,

Det. $\left|O B_{-} M A T\right|=-308648.8$.

The system $=$ observable since determinant $\neq$ zero.

The rank of Observability matrix $=2$ then all states are observable.

\section{Simulation procedure and result}

The strategy changed the input and output variables, ensuring the system's stable operation in sliding mode. The study's suspension is a quarter car sequential suspension with two degrees of freedom. The study's findings suggest that using the control strategy enhanced both the control objectives, as well as driver comfort and car ability to handle performance.

Figs. 4 to 6 reveal the first steps to applying the Bond graph for the quarter vehicle vertical for passive suspension system by using 20-SIM program.

The road profile has assumed a sine wave and input parameters had taken from Technical specifications of Honda Civic Lx Sedan 2019 [19] as the following: mass of

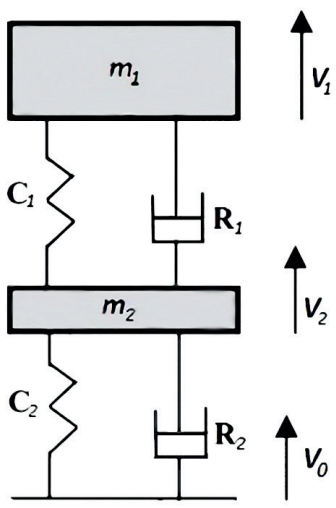

Fig. 4 Mechanical model for a vehicular suspension system 


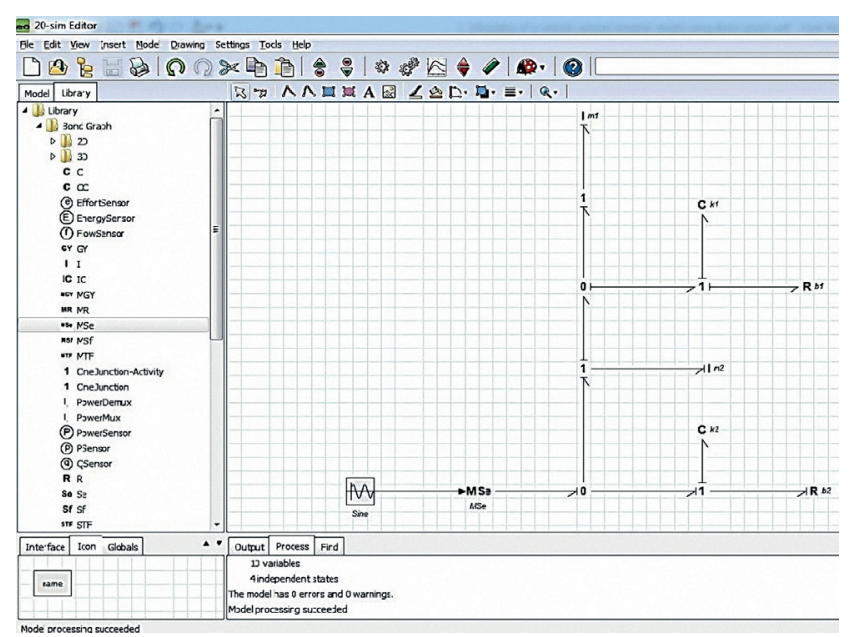

Fig. 5 Bond graph for the passive suspension of quarter vehicle vertical system with sine wave input by using 20 -SIM program

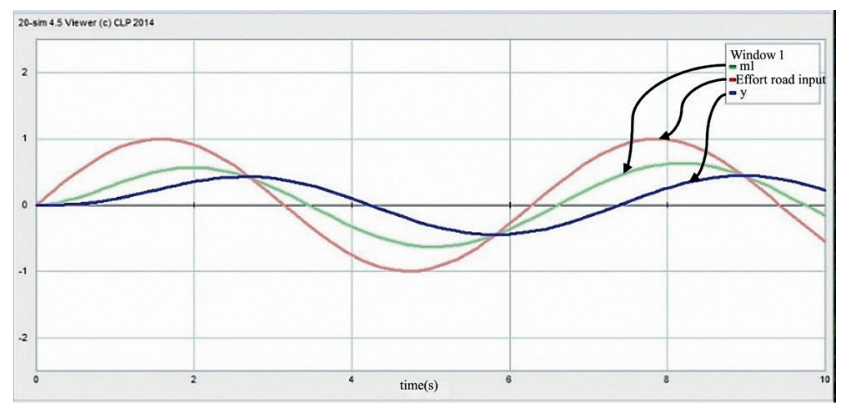

Fig. 6 Parameters for the system with the response of sinusoidal input

vehicle quarter of a vehicle $=360 \mathrm{~kg}$, mass of suspension system $=42 \mathrm{~kg}$, stiffness of spring $=200000 \mathrm{~N} / \mathrm{m}$

Damping coefficient of spring $=2000 \mathrm{~N} \mathrm{sec} / \mathrm{m}$, damping coefficient of tire $=183 \mathrm{~N} \mathrm{sec} / \mathrm{m}$, sinelomega $=6.28 \mathrm{rad} / \mathrm{sec}$, amplitude $=100$.

The relationship between the potential energy of mass of suspension system, effort and spring deflection with time in x-axis has exhibited in Fig. 6.

The Bond graph for the quarter vehicle vertical for a passive-suspension system with a step input as shown in Fig. 7. Whereas Fig. 8 reveals that the relationship between the mass of the car, effort of road and mass of wheel with time in $\mathrm{x}$-axis. Note that the vehicle vibrates with a higher road value less indicating a suspension.

The relationship between the potential energy for mass to the car has shown in Fig. 9, effort of road and the potential energy of wheel's mass of the unsprung- mass with time in $\mathrm{x}$-axis. The road profile assumed a step wave input.

When on the other hand Fig. 10 reveals the Bond graph for the quarter vehicle vertical for an active suspension system with constant input road displacement and Fig. 11 shows the Bond graph for the quarter vehicle vertical for an active suspension system with step input road displacement.

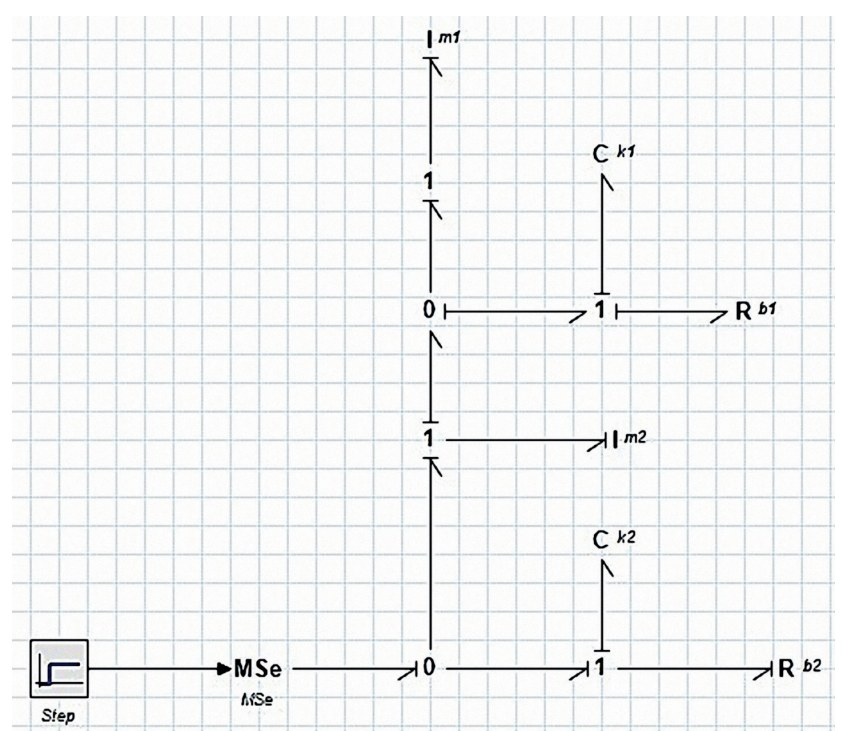

Fig. 7 Bond-graph for the passive-suspension of quarter vehicle vertical system with a step input

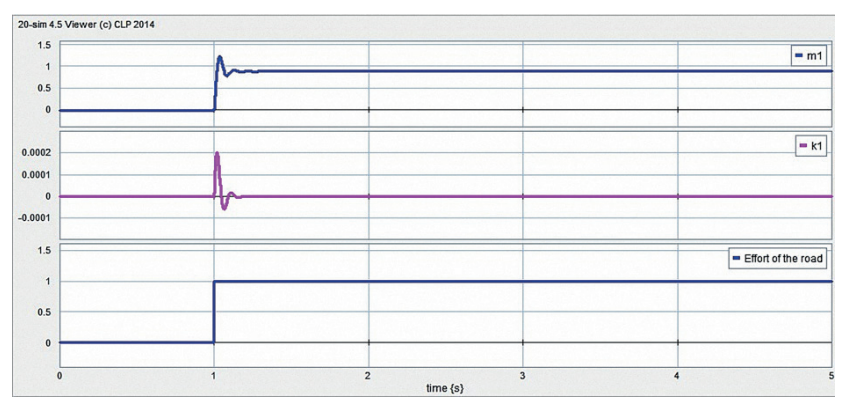

Fig. 8 Wheel displacement with road profile step input

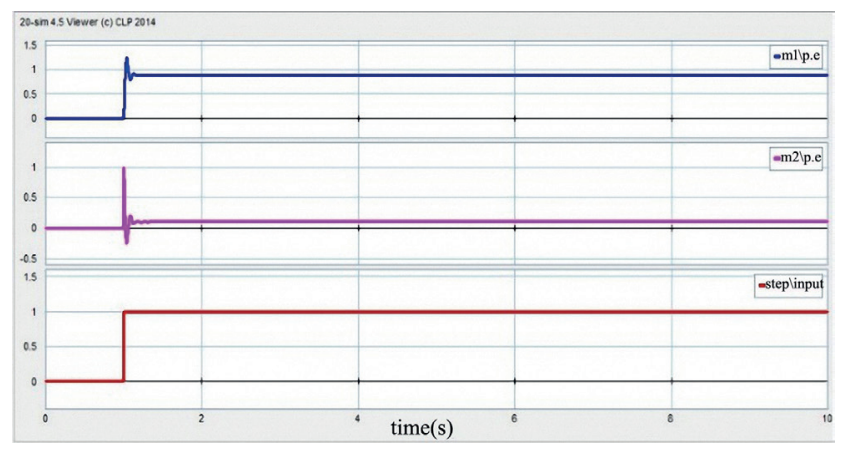

Fig. 9 Spring deflection, wheel displacement with road profile step input

Figs. 12 and 13 show the relationship between the mass of the car, effort of road and spring deflection with time in $\mathrm{x}$-axis of the active suspension. The road displacement assumed a step wave simulated using step input of $0.1 \mathrm{~m}$ with manipulated parameters to find out better performance.

\section{Comparison the system output with standard requirements}

As every manufacturing vehicle's company has own standard requirements then the comparison between them has 


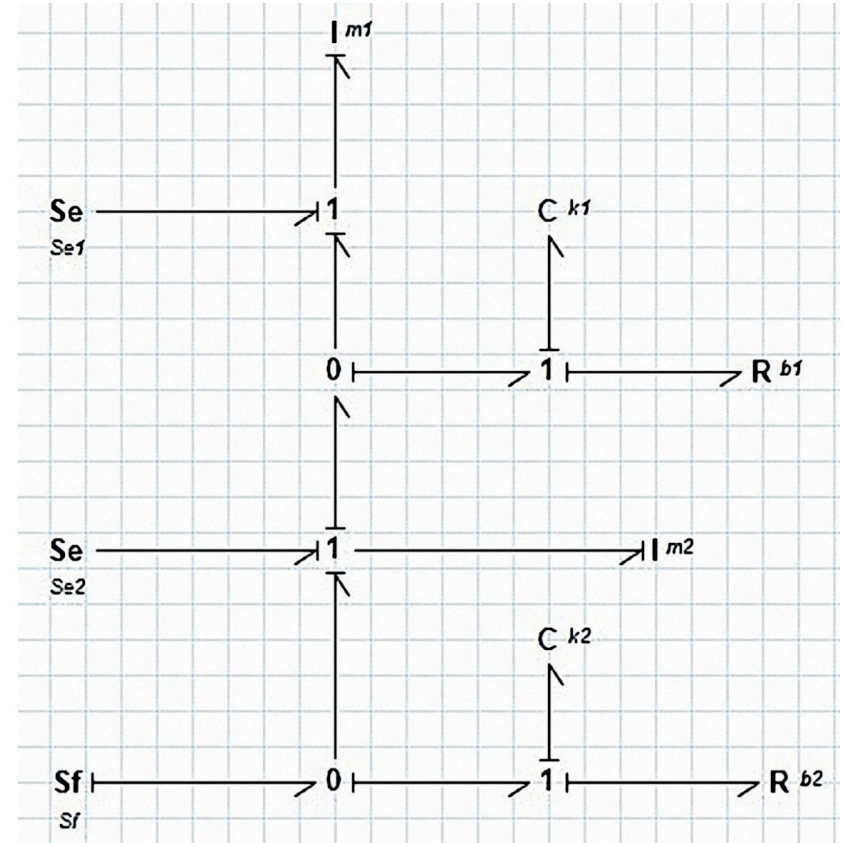

Fig. 10 Bond graph for the active-suspension of the quarter vehicle vertical system

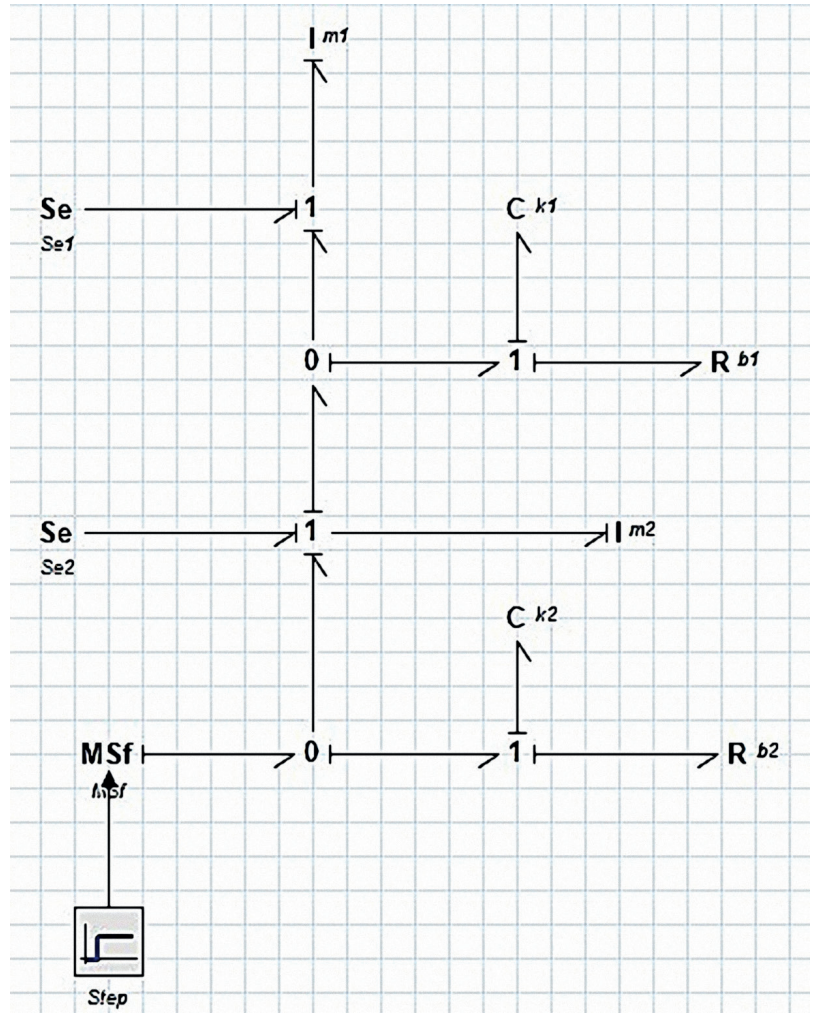

Fig. 11 Bond graph for an active suspension system with step wave input

issues but some of researching papers introduced a study of the suspension system that can make a comparison with it. The model modified in this case study is simulated using step input. The results of simulation are compared with the suspension displacement for various control algorithms introduced in the [20] as an example presented in Fig. 14.

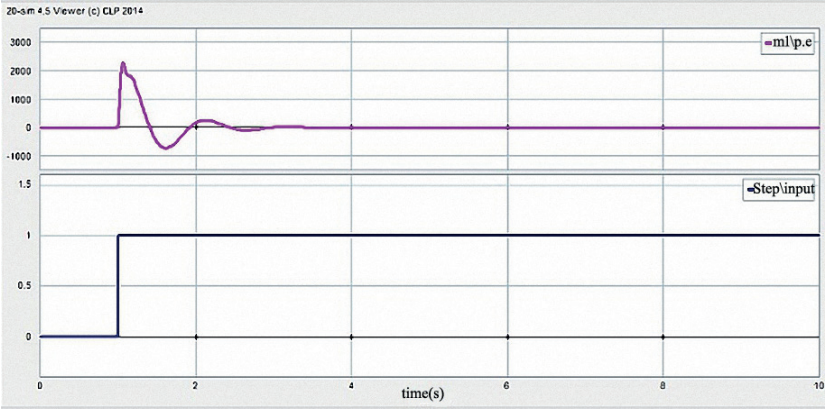

Fig. 12 The relationship between the potential energy of the mass of car and effort of road

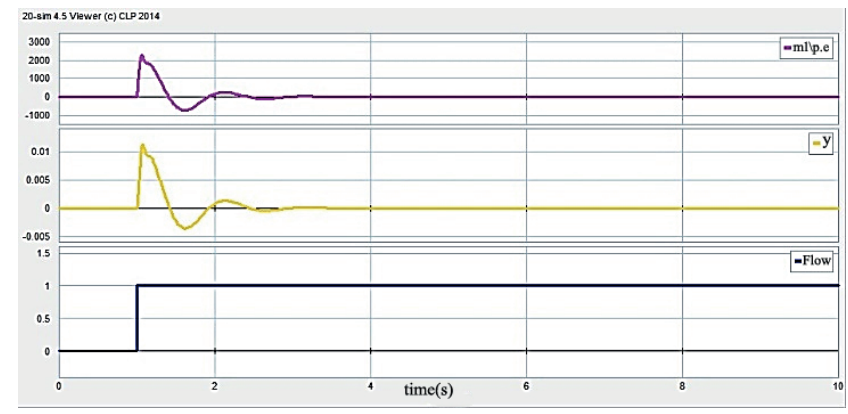

Fig. 13 The response of the mass' potential energy of the car with deflection also flow for the active suspension system

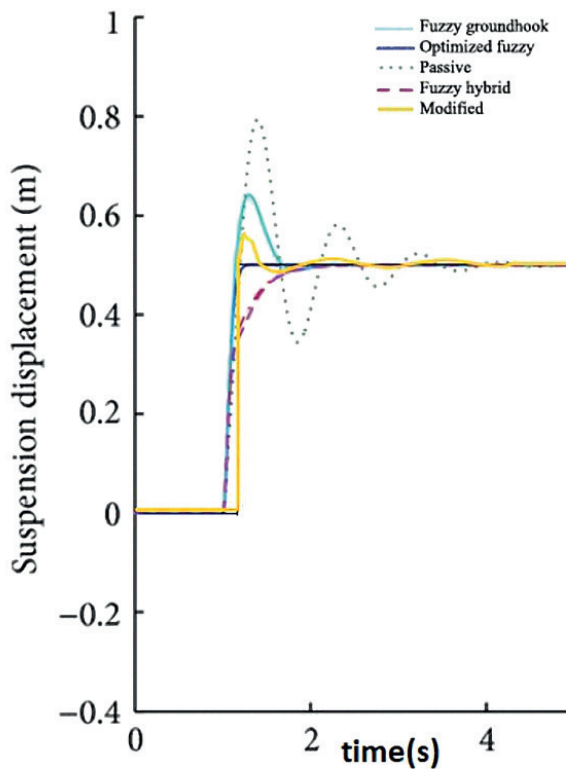

Fig. 14 The comparison of the suspension displacement for various control algorithms

\section{Conclusion}

It proposed an approach based definitely at the modeling approach recognized as a bond graph. Contemporary auto suspension constructions the usage of passive components simplest with the useful resource of the use of spring and damping coefficient with steady mode. Further, the results indicated that a stability machine is also required for the higher regular overall performance of the automobile. 
Lively suspension introduce an ability to utilize the conventional diagram to compromise amongst dealing with and luxurious via extend controlling the suspensions stress actuators. Gain a bond diagram illustration of the version studied to find out the fundamental dynamic's equations. Vehicle suspensions structures in many instances rated by its capability to provide appropriate street dealing with and decorate passenger consolation. Greater emphasis made on growing a cheap energetic suspension machine. Control machine needs to consist of the use of the delta delay function. Assessment between passive and vigorous suspensions machine executed by way of the use of high-quality types of street profiles. This technique has adequate flexibility that would possibly introduce different components in the vertical dynamic automobile model.

\section{References}

[1] Tamboli, J. A., Joshi, S. G. "Optimum design of a passive suspension system of a vehicle subjected to actual random road excitations", Journal of Sound and Vibration, 219(2), pp. 193-205, 1999.

https://doi.org/10.1006/jsvi.1998.1882

[2] Kropáč, O., Múčka, P. "Be careful when using the International Roughness Index as an indicator of road unevenness", Journal of Sound and Vibration, 287(4-5), pp. 989-1003, 2005. https://doi.org/10.1016/j.jsv.2005.02.015

[3] Fischer, D., Isermann, R. "Mechatronic semi-active and active vehicle suspensions", Control Engineering Practice, 12(11), pp. 1353-1367, 2004.

https://doi.org/10.1016/j.conengprac.2003.08.003

[4] Chantranuwathana, S., Peng, H. "Adaptive robust force control for vehicle active suspensions", International Journal of Adaptive Control and Signal Processing, 18(2), pp. 83-102, 2004. https://doi.org/10.1002/acs.783

[5] Koch, G., Fritsch, O., Lohmann, B. "Potential of low bandwidth active suspension control with continuously variable damper", Control Engineering Practice, 18(11), pp. 1251-1262, 2010. https://doi.org/10.1016/j.conengprac.2010.03.007

[6] Savaresi, S. M., Poussot-Vassal, C., Spelta, C., Sename, O., Dugard, L. "Semi-Active Suspension Technologies and Models", In: Savaresi, S. M., Poussot-Vassal, C., Spelta, C., Sename, O., Dugard, L. (eds.) Semi-Active- Suspension Control Design for Vehicles, Elsevier, Oxford, UK, 2010, pp. 15-39. https://doi.org/10.1016/B978-0-08-096678-6.00002-X

[7] Smith, M. C., Fu-Cheng Wang "Controller parameterization for disturbance response decoupling: application to vehicle activesuspension control", IEEE Transactions on Control Systems Technology, 10(3), pp. 393-407, 2002. https://doi.org/10.1109/87.998029

[8] Du, H., Zhang, N., Lam, J. "Parameter-dependent input-delayed control of uncertain vehicle suspensions", Journal of Sound and Vibration, 317(3-5), pp. 537-556, 2008. https://doi.org/10.1016/j.jsv.2008.03.066
Similarly, concerns ought to give the stableness effect of the suspension machine on the automobile.

\section{Nomenclature}

$\mathrm{m}_{2} \quad$ Wheel's mass $(\mathrm{kg})$

$\mathrm{m}_{1} \quad$ Vehicle's body mass $(\mathrm{kg})$

$C O \quad$ Controllability matrix

$O B \quad$ Observability matrix

$r \quad$ Road disturbance/road profile

$K \quad$ Stiffness (N/m)

$b \quad$ Damper constant ( $\mathrm{N} \mathrm{s} / \mathrm{m})$

I Moment of inertia $\left(\mathrm{kg} \mathrm{m}^{2}\right)$

$y \quad$ Vertical displacement of car body

$f(t) \quad$ The road excitation function

[9] Rozyn, M., Zhang, N. "A method for estimation of vehicle inertial parameters", Vehicle System Dynamics, 48(5), pp. 547-565, 2010. https://doi.org/10.1080/00423110902939863

[10] Park, J. H., Kim, Y. S. "Decentralized variable structure control for active suspensions based on a full-car model", In: Proceedings of the 1998 IEEE International Conference on Control Applications, Trieste, Italy, 1998, pp. 383-387. https://doi.org/10.1109/cca.1998.728460

[11] Kim, H.-J., Seok Yang, H., Park, Y.-P. "Improving the vehicle performance with active- suspension using road-sensing algorithm", Computers and Structures, 80(18-19), pp. 1569-1577, 2002. https://doi.org/10.1016/s0045-7949(02)00110-4

[12] Alasty, A., Ramezani, A. "Genetic Algorithm Based Parameter Identification of a Nonlinear Full Vehicle Ride Model", In: 2002 SAE Automotive Dynamics and Stability Conference and Exhibition, Detroit, MI, USA, 2002, Technical Paper number: 2002-01-1583.

https://doi.org/10.4271/2002-01-1583

[13] Yagiz, N., Hacioglu, Y. "Backstepping control of a vehicle with active suspensions", Control Engineering Practice, 16(12), pp. 1457-1467, 2008.

https://doi.org/10.1016/j.conengprac.2008.04.003

[14] Karnopp, D., Rosenberg, R., Perelson, A. S. "System Dynamics: A Unified Approach", IEEE Transactions on Systems, Man, and Cybernetics, SMC-6(10), pp. 724-724, 1976. https://doi.org/10.1109/tsmc.1976.4309434

[15] Breedveld, P. C. "Essential gyrators and equivalence rules for 3-port function structures", Journal of the Franklin Institute, 318(2), pp. 77-89, 1984. https://doi.org/10.1016/s0016-0032(84)90007-3

[16] Dauphin-Tanguy, G., Borne, P., Lebrun, M. "Order Reduction of Multi-time Scale Systems Using Bond Graphs, the Reciprocal System and the Singular Perturbation Method", Journal of the Franklin Institute, 319(1-2), pp. 157-171, 1985. https://doi.org/10.1016/0016-0032(85)90071-7 
[17] Chalh, Z., Frih, A., Mrabti, M., Alfidi, M. "Bond graph methodology for controllability of LTV systems", International Journal of Modelling, Identification and Control, 24(3), pp. 257-265, 2015. https://doi.org/10.1504/ijmic.2015.072622

[18] Darus, R., Sam, Y. M. "Modeling and control active suspension system for a full car model", In: 2009 5th International Colloquium on Signal Processing \& Its Applications, IEEE, Kuala Lumpur, Malaysia, 2009, pp. 13-18.

https://doi.org/10.1109/cspa.2009.5069178
[19] Honda "2019 Honda Civic Sedan: Vehicle Specifications", 2019. [online] Available at: https://owners.honda.com/vehicles/ information/2019/Civic-Sedan/specs\#mid\%5EFC2E6KEW [Accessed: 09 August 2019]

[20] Qazi, A. J., de Silva, C. W., Khan, A., Khan, M. T. "Performance Analysis of a Semiactive- Suspension System with Particle Swarm Optimization and Fuzzy Logic Control", The Scientific World Journal, 2014, Article ID 174102, 2014.

https://doi.org/10.1155/2014/174102 